\title{
不同管理措施对川西北草地土壤氮和碳特征的影响
}

孙庚 吴 宁* 罗 鹏

(中国科学院成都生物研究所, 成都 610041)

摘 要川西北地区是我国的主要牧区之一。草地承包后, 草地建设中出现了各种草地经营管理方式一一围栏、翻 耕和完全的人工建设。采用常规化学分析和气压过程分离 (Barometric Process Separation, BaPS)法, 对不同类型草地 (天 然放牧草地、围栏草地、翻耕草地和人工草地)的土壤氮、碳库以及反硝化速率、总硝化速率、 $\mathrm{N}_{2} \mathrm{O}$ 和 $\mathrm{CO}_{2}$ 排放速率进行 了研究。结果表明: 研究地点土壤有机质、全氮含量分别为 101.8 和 $5.1 \mathrm{~g}^{\bullet} \mathrm{kg}^{-1}$, 比典型的亚高山土壤有机质和全氮含 量( 分别是 181.3 和 $7.4 \mathrm{~g}^{\bullet} \mathrm{kg}^{-1}$ ) 明显低, 而且, 与通常的观念不同的是, 土壤 $\mathrm{NO}_{3}{ }^{-}-\mathrm{N}$ 含量是 $\mathrm{NH}_{4}{ }^{+}-\mathrm{N}$ 含量的 $3 \sim 11$ 倍。 这可能是由于研究地过度的人为干扰造成的。研究还发现, 不同管理措施对土壤氮、碳库, 氮转化速率和土壤呼吸 有显著影响。天然放牧草地围栏后, 土壤有机质和全氮含量明显升高, 比如, 围栏草地和翻耕草地的有机质、全氮 含量分别比天然放牧草地高 $61 \% 、 58 \%$ 和 $46 \% 、 51 \%$ 。氮转化速率和土壤呼吸大大加快, 尤其是在翻耕草地, 比如, 翻耕草地的总硝化速率和 $\mathrm{N}_{2} \mathrm{O}$ 排放速率分别是天然放牧草地的 5.1 和 2.4 倍。因此, 虽然春季翻耕可能提高作物 (包括牧草) 产量, 但它同时也承担了巨大的生态学风险, 包括增加排放到大气中的 $\mathrm{CO}_{2}$ 和 $\mathrm{N}_{2} \mathrm{O}$ 的量以及淋溶到地 下水的 $\mathrm{NO}_{3}$ - 的量。因此, 建议在川西北亚高山区的人工草地建设中慎重选择翻耕措施。研究还发现, 研究地土壤 的总硝化速率是净硝化速率的 $20 \sim 93$ 倍, 净硝化速率不能反映高海拔地区土壤硝化的准确状况。

关键词 川西北 亚高山草甸 草地管理 反硝化 总硝化

\section{CHARACTERISTICS OF SOIL NITROGEN AND CARBON OF PASTURES UNDER DIFFERENT MANAGEMENT IN NORTHWESTERN SICHUAN}

\author{
SUN Geng WU Ning** and LUO Peng \\ ( Chengdu Institute of Biology, Chinese Academy of Sciences, Chengdu 610041, China)
}

\begin{abstract}
Different methods of pasture management have been adopted in individualized pastures of northwestern Sichuan, one of the most important pastoral areas in China. In this paper, common analytical chemistry and barometric process separation methods were used to determine soil $\mathrm{N}$ and $\mathrm{C}$ pools, denitrification rates, gross nitrification rates, and $\mathrm{N}_{2} \mathrm{O}$ and $\mathrm{CO}_{2}$ flux rates of pastures under different management methods, including natural pasture, fenced pasture, tilled pasture and artificial pasture. The results indicated that SOM (Soil organic matter) and total $\mathrm{N}$ in soils of the study area were 101.8 and $5.1 \mathrm{~g}^{\bullet} \mathrm{kg}^{-1}$, respectively, which were notably lower than 181.3 and $7.4 \mathrm{~g} \bullet \mathrm{kg}^{-1}$ of other typical sub-alpine soils. In contrast to common belief, the content of $\mathrm{NO}_{3}{ }^{-}-\mathrm{N}$ was three-to-eleven times higher than that of $\mathrm{NH}_{4}{ }^{+}-\mathrm{N}$, which was probably caused by the anthropogenic disturbance. There was a significant effect of different methods of pasture management to $\mathrm{N}$ and $\mathrm{C}$ pools, $\mathrm{N}$ transformation rates and soil respiration. After fence, SOM and total $\mathrm{N}$ increased notably. For example, fenced pasture was $61 \%$ and $58 \%$ and tilled pasture was $46 \%$ and $51 \%$ higher than natural pasture in these two respects, respectively. Accordingly, $\mathrm{N}$ transformation rates and soil respiration rates accelerated a lot, especially in soils of tilled pasture. For example, in soils of tilled pasture gross nitrification and $\mathrm{N}_{2} \mathrm{O}$ flux rate were 5.1 times and 2.4 times that of natural pasture. Thus, although tillage in spring might help to enhanced crop yields (or pasturage), it also runs a great ecological risk including increased emissions of $\mathrm{CO}_{2}$ and $\mathrm{N}_{2} \mathrm{O}$ to the atmosphere and leaching of $\mathrm{NO}_{3}{ }^{-}$to ground water. This research also found that the gross nitrification rates were 20 - 93 times higher than net nitrification rates, and thus net nitrification rates do not provide valuable information on the dynamic character of soil nitrification in this high-altitude region.
\end{abstract}

Key words Northwestern Sichuan, Sub-alpine meadow, Pasture management, Denitrification, Gross nitrification

基金项目: 中国科学院重大项目 (KSCX1-07)、重要方向项目（KSCX2-01-09）、国家“十五”攻关项目（2001BA606A-05）以及四川省青年科技基 金项目 (03ZQ026-043) 
川西北地区由于其特有的和广阔的高寒草地生 态系统, 成为长江和黄河的重要水源涵养区, 同时也 构成了我国最为重要的畜牧业基地之一。这里的草 地面积占区域国土总面积的 $60 \%$, 畜牧业总产值占 农业总产值的 $55 \%$ 以上。同时, 该地区还是我国少 数几个生物多样性保存较好的地区之一, 与畜牧业 发展有关的牧草资源丰富, 蕴藏着十分丰富的特有 高山植物种类和野生动物资源。但由于近几十年来 人类不合理的开发利用, 川西北的草地已呈现出明 显的退化趋势, 草地承载力不断下降,退化面积已达 $40 \% \sim 60 \%$, 单位面积产草量比 20 世纪 60 年代初 期平均下降 25\% 50\% (陈文年等, 2002)。为了从 草地管理和社会经济发展角度建立综合而系统的措 施, 以抑制高寒草地的整体退化趋势, 从 1995 年以 来川西北牧区相继实施了以草地承包为核心的“三 配套”建设工程, 其中, 围栏和人工草地建植是草地 建设中的两项重要内容, 而春季翻耕往往又是人工 草地建设中采取的重要技术措施之一。目前,这些 技术措施已被应用到西部绝大多数牧区开始实施的 “退牧还草”工程当中, 但这些措施除了给地上的生物 群落带来明显影响之外, 对地表之下的土壤, 特别是 由于其青藏高原背景, 对土壤氮、碳库及其转化速率 到底有什么样的影响？是本文所关注的核心问题。

众所周知, 人类活动包括人类不同的土地经营 管理措施, 不仅会直接导致自然植被发生相应的变 化, 同时还深刻地影响着生态系统的物质循环, 其中 一个重要的方面是对土壤氮和碳循环的影响 ( Hachl et al., 2000）。而且,这种作用还可通过更大空间尺 度上系统的物质循环使其效应波及到整个区域甚至 全球 (Franzluebbers, 1999)。因此, 不同管理措施对 土壤氮、碳库及其转化速率的影响也已成为全球变 化研究中一个十分重要的方面。目前, 国内外对不 同管理措施条件下土壤氮和碳特征的研究比较多

(Hadi et al.,2000; Dao, 1998; Davidson et al., 1992;

Estavillo et al ., 2002; Holt, 1997; 柳丽萍和廖仰南, 1997; 庞学勇等, 2002), 但是针对川西北高寒牧区草 地管理出现的碳氮变化特征所开展的研究尚属空 白。本研究正是针对牧区迅速发展中的实际需求, 在川西北牧区选择了 4 种典型经营管理措施影响下 的草地一一围栏草地 (只围栏)、翻耕草地 (围栏并翻 耕)、人工草地(除杂后, 播种、施肥)和天然放牧草地 (重度放牧)进行研究, 目的是探讨不同措施对土壤 氮、碳库及其转化速率的影响, 为制定科学的土地利 用规划和进行生态系统的有效管理提供依据。

\section{1 材料和方法}

\section{1 研究区域}

由于实施家庭草场承包后,每户按要求建立的 人工草场多位于牧民的冬草场 (冬房附近), 为保证 不同类型之间的可比性, 研究地点选择在四川省西 北部主要牧区县之一的松潘县, 将卡卡沟 (海拔 $3400 \mathrm{~m}, 103^{\circ} 41^{\prime} \mathrm{E}, 32^{\circ} 59^{\prime} \mathrm{N}$ ) 作为主要的野外采样地 点。该区域次生性的亚高山草甸被认为主要是由于 人为砍伐、火烧和过度放牧形成的 (吴宁和刘照光, 1998), 是传统游牧中所用之冬场。区域气候主要受 高原大地形影响, 冬半年主要由来自北方和高原的 冷高压控制, 夏半年主要为来自低纬度的西南和东 南暖湿气流控制。气温变化快, 昼夜温差大。该地 带的年平均气温为 $2.8{ }^{\circ} \mathrm{C}, 1$ 月均温 $-7.6{ }^{\circ} \mathrm{C}, 7$ 月 均温 $11.7{ }^{\circ} \mathrm{C}$, 无绝对无霜期, $\geqslant 10{ }^{\circ} \mathrm{C}$ 年积温 $428.6{ }^{\circ} \mathrm{C}$; 年平均降水量 $717.7 \mathrm{~mm}$, 其中 $80 \%$ 集中在 5 10 月。研究区域内的成土母质为寒冻风化物和 冰碛物, 以山地暗棕壤为主, 土层较厚, 自然肥力较 高(刘世全, 1996)。

为了比较不同管理措施对草地土壤的影响, 选 择 4 种草地一一然放牧草地、围栏草地、翻耕草地 和人工草地进行研究。具体试验实施过程如下: 在 2001 年 9 月对部分放牧草地进行围栏; 又从 2002 年 4 月开始, 每年春季对部分围栏草地进行深度翻耕。 人工草地是在 2001 年春经人工除杂、播撒牧草 (垂 穗披碱草 Elymus nutans) 种子后建立起来的, 同时每 年的春季施用化肥 (尿素和过磷酸钙混合物 300 $\left.\mathrm{kg} \bullet \mathrm{hm}^{-2}\right)$ 。围栏草地、翻耕草地和人工草地建立 后, 均无牲畜采食或人工则割。放牧草地选择相邻 的、放牧影响明显的草场。

\section{2 野外调查和取样}

样地设置和取样: 分别在 4 种典型的不同管理 措施的草地中设置样地, 样地大小均为 $10 \mathrm{~m} \times 10 \mathrm{~m}$ 。 除管理措施不同之外, 样地设置尽量考虑到在地形 (坡向、坡度、微地形)和成土母质等方面基本一致。

样地调查: 样地调查的内容包括,物种组成、盖 度、多度、生物量。用土壤温度计和水分测定仪获取 土壤温度和湿度方面的数据。

分别在 2003 年 4 月中旬、7 月下旬和 8 月下旬 取土样。3 次取样均是随机取土壤表面以下约 15 $\mathrm{cm}$ 处土样; 每个样地每次取一般土样 6 个, 3 次共获 得土样 72 份。每份土样分别进行 $\mathrm{pH}$ 值、有机质、全 氮、 $\mathrm{NH}_{4}{ }^{+}-\mathrm{N}$ 和 $\mathrm{NO}_{3}{ }^{-}-\mathrm{N}$ 的分析。为测定植物生长旺 
盛季节 (当地为 7 月下旬至 8 月下旬)的土壤净硝化 和净矿化速率, 在 7 月下旬取一般土样的同时, 放置 埋藏袋 (Knoepp \& Swank, 1995), 埋藏深度为土壤表 面以下 $10 \sim 20 \mathrm{~cm}$, 埋藏时间为 $30 \mathrm{~d}$ 整。在 8 月下旬 取一般土样的同时, 在每个样地随机设置 5 个取样 点, 每个取样点用环刀取原状土样 4 个, 共获得原状 土样 80 份, 用来做反硝化、总硝化、 $\mathrm{N}_{2} \mathrm{O}$ 和 $\mathrm{CO}_{2}$ 排放 速率的分析。

在取得土样后, 用装有冰的泡沫箱带回实验室, 立即分析。

\section{3 分析方法}

有机质、全氮、 $\mathrm{NH}_{4}{ }^{+}-\mathrm{N}$ 和 $\mathrm{NO}_{3}{ }^{-}$等的化学分析 方法: 土壤容重采用环刀法, 含水量采用烘干法, $\mathrm{pH}$ 值采用电位法 (GB7859-87), 有机质采用硫酸-重铬 酸钾法 (GB7857-87), 全氮采用半微量凯氏法 (GB7173-87), $\mathrm{NH}_{4}{ }^{+}-\mathrm{N}$ 采用氯化钾提取-靛酚蓝比色 法, $\mathrm{NO}_{3}{ }^{-}-\mathrm{N}$ 采用硫酸钻提取-酚二磺酸法 (鲁如坤, 2000)。

反硝化、总硝化、 $\mathrm{N}_{2} \mathrm{O}$ 和 $\mathrm{CO}_{2}$ 排放速率的仪器测 定方法: 应用气压过程分离法 (Barometric ProcessSeparation, BaPS, 仪器由德国 UMS GmbH 公司生产, Fraunhofer Institute for Atmospherically Environment Research 研发) 对环刀取的原状土样进行测定获得。

土壤中的硝化过程是一个净气体消耗的过程, 将导致密闭系统内压力下降:

$\mathrm{NH}_{4}{ }^{+}+2 \mathrm{O}_{2} \rightarrow \mathrm{NO}_{3}{ }^{-}+\mathrm{H}_{2} \mathrm{O}+2 \mathrm{H}^{+}$

反硝化过程是一个净气体产生的过程, 将导致 密闭系统内压力升高:

$5 \mathrm{CH}_{2} \mathrm{O}+4 \mathrm{NO}_{3}{ }^{-}+4 \mathrm{H}^{+} \rightarrow 5 \mathrm{CO}_{2}+7 \mathrm{H}_{2} \mathrm{O}+2 \mathrm{~N}_{\mathrm{x}} \mathrm{O}_{\mathrm{y}}$ $\left(\mathrm{N}_{\mathrm{x}} \mathrm{O}_{\mathrm{y}}\right.$ 代表 $\mathrm{N}_{2} 、 \mathrm{~N}_{2} \mathrm{O} 、 \mathrm{NO}$ 等含氮气体混合物)

如果在土壤呼吸过程中只考虑 $\mathrm{O}_{2}$ 的消耗和 $\mathrm{CO}_{2}$ 的产生, 那么土壤呼吸既不产生气体也不消耗 气体, 使密闭系统内的压力保持不变:

\section{$\mathrm{CH}_{2} \mathrm{O}+\mathrm{O}_{2} \rightarrow \mathrm{CO}_{2}+\mathrm{H}_{2} \mathrm{O}$}

但是土壤中产生的 $\mathrm{CO}_{2}$ 并不完全的排放到大气 中去, 其中的一部分将溶解在土壤溶液中 (并且 $\mathrm{CO}_{2}$ 的溶解度随温度变化), 使得 $\mathrm{CO}_{2}$ 的分压降低。与 $\mathrm{CO}_{2}$ 不同的是, $\mathrm{N}_{2} \mathrm{O}$ 的这种溶解效应未被考虑, 因为 $\mathrm{N}_{2} \mathrm{O}$ 所占分压与 $\mathrm{CO}_{2}$ 相比是微不足道的 (在实验开 始阶段, 甚至小于 3 个数量级)。

综合土壤硝化、反硝化和土壤呼吸 3 个过程, 并 考虑 $\mathrm{CO}_{2}$ 在土壤溶液中的溶解和温度补偿效应, $\mathrm{BaPS}$ 仪通过直接测量密闭系统内原状土样上方
$\mathrm{CO}_{2} 、 \mathrm{O}_{2}$ 和总压力的变化, 就可以准确的给出反硝化 速率、总硝化速率、 $\mathrm{N}_{2} \mathrm{O}$ 和 $\mathrm{CO}_{2}$ 排放速率的瞬时值和 一段时间内的平均值。具体的推导过程和计算公式 见文献( Ingwersen et al. , 1999)。

它的优点是: 1) 能够快速获得结果 (一般只需 $12 \mathrm{~h}$ ); 2) 能够更方便地研究土壤温度和湿度对硝化 和反硝化等的影响; 3 ) 不需要标记物质 (如 ${ }^{15} \mathrm{~N}$ ) 和抑 制性气体 (如乙炔) 的介入, 从而不会改变土壤结构 和微生物过程。在不同生境条件下, 把 BaPS 法与 ${ }^{15} \mathrm{~N}$ 标记法和乙炔抑制法的测定结果进行比较, 得出 结论: BaPS 法与上述两种方法的结果有很好的一致 性（Ingwersen et al., 1999）。但是, 这种方法不适合 通气状况极不好的土壤。

反硝化速率、总硝化速率和气体排放速率是在 8 月平均土壤温度和含水量的条件下进行测定的; 5 个取样点分别测定, 每次测定应用同一取样点的 3 个环刀原状土样。

\section{4 统计分析}

应用统计分析软件 SPSS, 分别对不同土壤指标 (有机质、全氮、 $\mathrm{NH}_{4}{ }^{+}-\mathrm{N} 、 \mathrm{NO}_{3}^{-}-\mathrm{N}$ 、反硝化速率、总硝 化速率、 $\mathrm{N}_{2} \mathrm{O}$ 和 $\mathrm{CO}_{2}$ 排放速率) 做单因素(管理措施: 天然放牧、围栏、围栏 + 翻耕、人工) 方差分析得出不 同管理措施草地的标准偏差, 判别其间是否有显著 差异; 分别对不同管理措施草地 (天然放牧地、围栏 草地、翻耕草地和人工草地) 土壤各种指标 (有机质、 全氮、 $\mathrm{NH}_{4}{ }^{+}-\mathrm{N} 、 \mathrm{NO}_{3}{ }^{-}-\mathrm{N}$ 、反硝化速率、总硝化速率、 $\mathrm{N}_{2} \mathrm{O}$ 和 $\mathrm{CO}_{2}$ 排放速率) 间进行相关分析, 以说明这些 指标两两之间的内在联系。

\section{2 实验结果}

\section{1 有机质、全氮、 $\mathrm{NH}_{4}{ }^{+}-\mathrm{N}$ 和 $\mathrm{NO}_{3}{ }^{-}-\mathrm{N}$ 含量的比较} 在表 2 中可以看到, 在不同经营管理措施影响 下草地的土壤有机质和全氮含量有明显的不同: 1) 人工草地在有机质和全氮含量方面都是最高的, 而 天然放牧草地则最低, 前者分别是后者的 2.1 和 3.1 倍(7月)。2) 比较围栏草地和天然放牧草地, 可以 发现在天然放牧草地围栏并排除人为干扰后, 土壤 有机质和全氮含量分别上升了 $61 \%$ 和 $58 \%$ 。3) 比 较翻耕草地和围栏草地可以发现, 土壤翻耕后土壤 有机质含量下降 $9.2 \%$, 但全氮含量下降不明显 (差 异不显著)。4) 翻耕草地的有机质和全氮含量比天 然放牧草地分别高 $46 \%$ 和 $51 \%$ 。

在不同经营管理措施影响下草地土壤的 $\mathrm{NH}_{4}{ }^{+}-\mathrm{N}$ 含量差异不明显( 除了天然放牧草地明显偏 
表 1 研究地点的土壤和植被

Table 1 Vegetation and soil characteristics of study area

\begin{tabular}{|c|c|c|c|c|c|}
\hline $\begin{array}{c}\text { 草地类型 } \\
\text { Types of pasture }\end{array}$ & $\begin{array}{c}\text { 容重 } \\
\text { Bulk density } \\
\left(\mathrm{g}^{\bullet} \mathrm{cm}^{-3}\right)\end{array}$ & $\mathrm{pH}$ & $\begin{array}{l}8 \text { 月平均土壤温度 } \\
\text { Soil mean temperature } \\
\text { in August }\left({ }^{\circ} \mathrm{C}\right)\end{array}$ & $\begin{array}{l}8 \text { 月平均土壤含水量 } \\
\text { Soil mean moisture } \\
\text { in August }\left(\mathrm{kg}^{\bullet} \mathrm{kg}^{-1}\right)\end{array}$ & $\begin{array}{c}\text { 主要植物种类 } \\
\text { Main plant species }\end{array}$ \\
\hline $\begin{array}{l}\text { 天然放牧草地 } \\
\text { Natural pasture }\end{array}$ & 1.344 & 6.42 & 13.3 & 0.31 & $\begin{array}{l}\text { 从生苔草 ( Carex caespifosa)、腋花马先蒿 } \\
\text { (Pedicularis axillaris)、多茎委陵菜 ( Potentilla } \\
\text { lancinata) }\end{array}$ \\
\hline $\begin{array}{l}\text { 围栏草地 } \\
\text { Fenced pasture }\end{array}$ & 1.268 & 6.21 & 13.7 & 0.34 & $\begin{array}{l}\text { 光盘早熟禾 ( Poa elanataleng)、腋花马先蒿 } \\
\text { (Pedicularis axillaris)、多茎委陵菜 ( Potentilla } \\
\text { lancinata) }\end{array}$ \\
\hline $\begin{array}{l}\text { 翻耕草地 } \\
\text { Tilled pasture }\end{array}$ & 1.018 & 6.30 & 14.0 & 0.37 & $\begin{array}{l}\text { 四齿蚤缀 ( Arenaria quadridentata)、腋花马先 } \\
\text { 蒿 ( Pedicularis axillaris)、多茎委陵菜 ( Poten- } \\
\text { tilla lancinata) }\end{array}$ \\
\hline $\begin{array}{l}\text { 人工草地 } \\
\text { Artificial pasture }\end{array}$ & 1.185 & 6.25 & 16.5 & 0.32 & 垂穗披碱草 Elymus nutans \\
\hline
\end{tabular}

表 27 月和 8 月不同管理措施草地的有机质、全氮、 $\mathrm{NH}_{4}{ }^{+}-\mathrm{N}^{-} \mathrm{NO}_{3}{ }^{-}-\mathrm{N}$ 含量

Table 2 Soil organic matter ( $\mathrm{SOM}$ ), total $\mathrm{N}, \mathrm{NH}_{4}{ }^{+}-\mathrm{N}$ and $\mathrm{NO}_{3}{ }^{-}-\mathrm{N}$ of pastures under different managements in July and August

\begin{tabular}{|c|c|c|c|c|c|c|c|}
\hline \multirow{2}{*}{$\begin{array}{c}\text { 草地类型 } \\
\text { Types of pasture }\end{array}$} & \multicolumn{5}{|c|}{7 月 July } & \multicolumn{2}{|c|}{8 月 August } \\
\hline & $\begin{array}{c}\text { 有机质 SOM } \\
\left(\mathrm{g} \cdot \mathrm{kg}^{-1}\right)\end{array}$ & $\begin{array}{c}\text { 全氮 Total N } \\
\left(\mathrm{g}^{\bullet} \mathrm{kg}^{-1}\right)\end{array}$ & $\mathrm{C} / \mathrm{N}$ & $\begin{array}{c}\mathrm{NH}_{4}{ }^{-}-\mathrm{N} \\
\left(\mathrm{mg} \bullet \mathrm{kg}^{-1}\right)\end{array}$ & $\begin{array}{c}\mathrm{NO}_{3}{ }^{-}-\mathrm{N} \\
\left(\mathrm{mg} \cdot \mathrm{kg}^{-1}\right)\end{array}$ & $\begin{array}{c}\mathrm{NH}_{4}{ }^{-}-\mathrm{N} \\
\left(\mathrm{mg} \cdot \mathrm{kg}^{-1}\right)\end{array}$ & $\begin{array}{c}\mathrm{NO}_{3}{ }^{-}-\mathrm{N} \\
\left(\mathrm{mg}^{\bullet} \mathrm{kg}^{-1}\right)\end{array}$ \\
\hline 天然放牧草地 & 69.71 & 3.74 & \multirow{2}{*}{10.81} & 1.08 & 13.27 & 4.37 & 20.82 \\
\hline Natural pasture & $\pm 3.40^{\mathrm{d}}$ & $\pm 0.008^{\mathrm{c}}$ & & $\pm 0.03^{\mathrm{b}}$ & $\pm 1.30^{\mathrm{b}}$ & $\pm 0.11^{\mathrm{b}}$ & $\pm 8.39^{\mathrm{a}}$ \\
\hline 围栏草地 & 112.39 & 5.92 & \multirow{2}{*}{11.01} & 1.95 & 9.23 & 5.25 & 23.85 \\
\hline Fenced pasture & $\pm 3.04^{\mathrm{b}}$ & $\pm 0.02^{\mathrm{b}}$ & & $\pm 0.08^{\mathrm{a}}$ & $\pm 0.81^{\mathrm{c}}$ & $\pm 0.03^{\mathrm{a}}$ & $\pm 0.24^{\mathrm{a}}$ \\
\hline 翻耕草地 & 102.00 & 5.65 & \multirow{2}{*}{10.47} & 2.14 & 6.79 & 4.80 & 20.85 \\
\hline Tilled pasture & $\pm 8.71^{\mathrm{c}}$ & $\pm 0.002^{\mathrm{b}}$ & & $\pm 0.04^{\mathrm{a}}$ & $\pm 0.53^{\mathrm{d}}$ & $\pm 0.01^{\mathrm{a}}$ & $\pm 0.86^{\mathrm{a}}$ \\
\hline 人工草地 & 144.64 & 11.51 & \multirow{2}{*}{7.29} & 2.29 & 20.44 & 5.42 & 22.90 \\
\hline Artificial pasture & $\pm 0.75^{\mathrm{a}}$ & $\pm 0.007^{\mathrm{a}}$ & & $\pm 0.007^{\mathrm{a}}$ & $\pm 0.32^{\mathrm{a}}$ & $\pm 0.03^{\mathrm{a}}$ & $\pm 1.79^{\mathrm{a}}$ \\
\hline
\end{tabular}

表中值为平均值 \pm 标准偏差, 相同字母表示无显著性差异 $(p<0.05)$ Data of the table are means \pm standard deviation. Common superscripts within columns indicate no significant differences $(p<0.05)$ between means

表 3 不同管理措施草地土壤的反硝化、总硝化、 $\mathrm{N}_{2} \mathrm{O}$ 和 $\mathrm{CO}_{2}$ 的排放速率

Table 3 Denitrification, gross nitrification, $\mathrm{N}_{2} \mathrm{O}$ and $\mathrm{CO}_{2}$ flux rates of pasture under different management methods

\begin{tabular}{lcccc}
\hline $\begin{array}{c}\text { 草地类型 } \\
\text { Types of pasture }\end{array}$ & $\begin{array}{c}\text { 反硝化速率 } \\
\text { Denitrification rate } \\
\left(\mathrm{mg} \mathrm{N} \cdot \mathrm{kg}^{-1} \cdot \mathrm{d}^{-1}\right)\end{array}$ & $\begin{array}{c}\text { 总硝化速率 } \\
\text { Gross nitrification rate } \\
\left(\mathrm{mg} \mathrm{N} \cdot \mathrm{kg}^{-1} \cdot \mathrm{d}^{-1}\right)\end{array}$ & $\begin{array}{c}\mathrm{N}_{2} \mathrm{O} \text { 排放速率 } \\
\mathrm{N}_{2} \mathrm{O} \text { flux rate } \\
\left(\mathrm{g} \mathrm{N} \mathrm{N}_{2} \mathrm{~kg}^{-1} \cdot \mathrm{d}^{-1}\right)\end{array}$ & $\begin{array}{c}\mathrm{CO}_{2} \text { 排放速率 } \\
\mathrm{CO}_{2} \text { flux rate } \\
\left(\mathrm{g} \mathrm{CO} \mathrm{CO}_{2} \cdot \mathrm{kg}^{-1} \cdot \mathrm{d}^{-1}\right)\end{array}$ \\
\hline 天然放牧草地 Natural pasture & $2.54 \pm 1.06^{\mathrm{c}}$ & $6.66 \pm 0.38^{\mathrm{d}}$ & $0.0051 \pm 0.0019^{\mathrm{b}}$ & $0.23 \pm 0.13^{\mathrm{d}}$ \\
围栏草地 Fenced pasture & $3.42 \pm 0.54^{\mathrm{b}}$ & $7.40 \pm 1.20^{\mathrm{c}}$ & $0.0070 \pm 0.0036^{\mathrm{b}}$ & $0.69 \pm 0.42^{\mathrm{c}}$ \\
翻耕草地 Tilled pasture & $5.99 \pm 1.18^{\mathrm{a}}$ & $33.92 \pm 3.76^{\mathrm{a}}$ & $0.012 \pm 0.0049^{\mathrm{a}}$ & $2.73 \pm 0.60^{\mathrm{a}}$ \\
人工草地 Artificial grassland & $3.66 \pm 0.96^{\mathrm{b}}$ & $9.44 \pm 1.52^{\mathrm{b}}$ & $0.0074 \pm 0.0037^{\mathrm{b}}$ & $1.76 \pm 0.34^{\mathrm{b}}$ \\
\hline
\end{tabular}

表中值为平均值 \pm 标准偏差, 相同字母表示无显著性差异 $(p<0.05)$ Data of the table are means \pm standard deviation. Common superscripts within columns indicate no significant differences $(p<0.05)$ between means

低), 而 $\mathrm{NO}_{3}{ }^{-}-\mathrm{N}$ 含量在野外埋藏前 (7 月) 差异明显, 之后 ( 8 月)变得几乎没有差异(表 2 )。

2.2 反硝化、总硝化、 $\mathrm{N}_{2} \mathrm{O}$ 和 $\mathrm{CO}_{2}$ 排放速率的比较 从表 3 可以发现, 不同经营管理措施对转化速 率的影响存在较大差异: 1 ) 比较围栏草地和天然放 牧草地发现, 除 $\mathrm{N}_{2} \mathrm{O}$ 排放速率差异不明显外, 围栏 草地的反硝化、总硝化和 $\mathrm{CO}_{2}$ 排放速率都高于放牧 草地, 如前者的反硝化速率比后者高 $34.8 \%, \mathrm{CO}_{2}$ 排 放速率前者是后者的 3 倍。2) 比较翻耕草地和围栏
草地, 发现翻耕后, 反硝化、总硝化、 $\mathrm{CO}_{2}$ 排放速率分 别升高了 $67 \% 、 360 \%$ 和 396\%。3) 翻耕草地的上述 各项指标明显高于天然放牧草地, 总硝化速率和 $\mathrm{N}_{2} \mathrm{O}$ 排放速率分别是天然放牧草地的 5.1 和 2.4 倍。4)人工草地的反硝化、总硝化和 $\mathrm{CO}_{2}$ 排放速率 低于翻耕草地, 而略高于围栏草地, 但都远远高于天 然放牧草地。

图 1 4 中是不同管理措施草地土壤反硝化、总 硝化、 $\mathrm{N}_{2} \mathrm{O}$ 和 $\mathrm{CO}_{2}$ 排放速率的比较。 


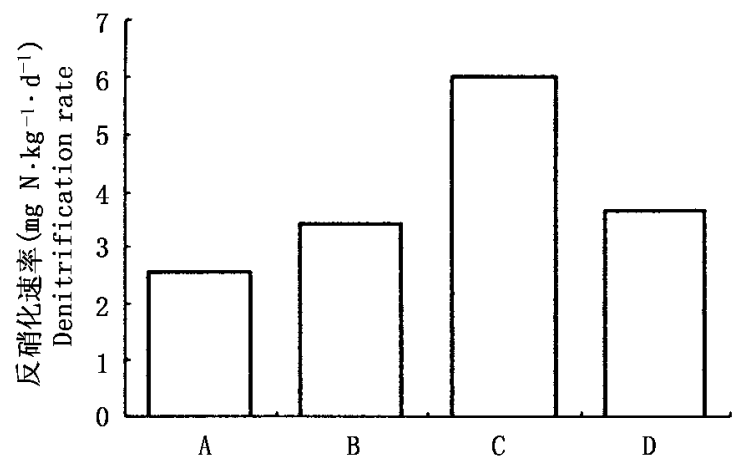

图 1 不同管理措施草地的土壤反硝化速率

Fig. 1 Denitrification rate of pastures under different managements

A: 天然放牧地 Natural pasture B: 围栏草地 Fenced pasture C: 翻 耕草地 Tilled pasture D: 人工草地 Artificial grassland

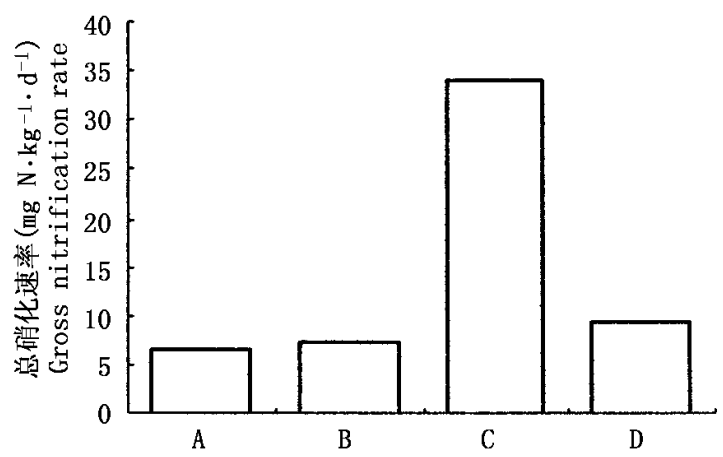

图 2 不同管理措施草地的土壤总硝化速率

Fig. 2 Gross nitrification rate of pastures under different managements A, B, C, D: 同图 1 See Fig. 1

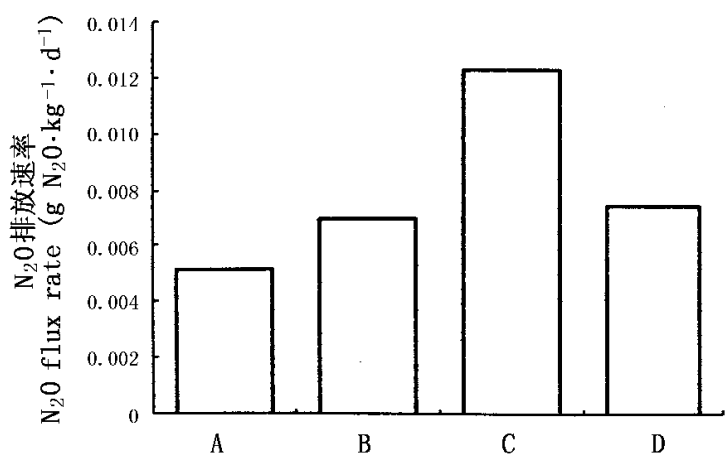

图 3 不同管理措施草地的土壤 $\mathrm{N}_{2} \mathrm{O}$ 排放速率

Fig. $3 \mathrm{~N}_{2} \mathrm{O}$ flux rate of pastures under different managements

A, B, C, D: 同图 1 See Fig. 1

\section{3 总硝化速率与净硝化速率的比较}

从表 4 中可以看到, 在不同管理措施影响下的 草地土壤中总硝化速率远高于净硝化速率, 总硝化 速率是净硝化速率的 $20 \sim 93$ 倍。翻耕草地的总硝 化速率又远大于其它各类型。

3 讨 论

3.1 人类干扰历史对土壤氮和碳特征的影响

研究地的亚高山草甸被认为主要是由于人类的
砍伐、火烧和过度放牧形成的 (吴宁和刘照光, 1998）。这种长期的人类干扰历史在土壤氮、碳方面 产生了深刻影响。例如, 与邻近的亚高山原始针叶 林内的土壤比较, 研究区域草地土壤的有机质和全 氮含量明显偏低。在相似海拔的亚高山原始针叶林 （云杉林 Picea forest）土壤中, 有机质和全氮含量平 均为 181.3 和 $7.4 \mathrm{~g} \bullet \mathrm{kg}^{-1}$ (庞学勇等, 2002), 而本研究 地点各类型草地的平均值为 101.8 和 $5.1 \mathrm{~g} \bullet \mathrm{kg}^{-1}$, 分别偏低 44\% 和 30\%。分析其原因, 干扰导致的逆 向演替 (从森林到草地) 无疑使归还到土壤中的调落 物量减少, 从而使得土壤中包括氮元素在内的营养 物质含量不断降低。

一般来说, 在酸性的高山草甸土壤中, $\mathrm{NH}_{4}{ }^{+}-\mathrm{N}$ 含量高于 $\mathrm{NO}_{3}{ }^{-}-\mathrm{N}$ ( Körner, 1999), 但本研究发现: 在 7 月, 研究地区土壤的 $\mathrm{NO}_{3}{ }^{-}-\mathrm{N}$ 含量是 $\mathrm{NH}_{4}{ }^{+}-\mathrm{N}$ 含量的 3 11 倍; 这个数值在 4 月更高。其可能的原因主 要有两个: 1)研究地点为位于林线以下的亚高山地 带, 较之与林线以上的高山带, 植物和微生物更多地 消耗了土壤中的 $\mathrm{NH}_{4}{ }^{+}-\mathrm{N} ; 2$ ) 在位于亚高山带的冬季 草场中, 土壤具有较强的硝化作用。4 种土地管理 措施条件下土壤的 $\mathrm{pH}$ 值平均为 6.35 , 而较高的 $\mathrm{pH}$ 值将促进硝化作用, 从而有利于 $\mathrm{NO}_{3}{ }^{-}-\mathrm{N}$ 的积累, 但 出现强硝化作用的更主要原因可能来自人类活动干 扰的作用。不同管理措施条件下的草地都承受着或 曾经受到过强烈的人类干扰影响, 这些人类活动通

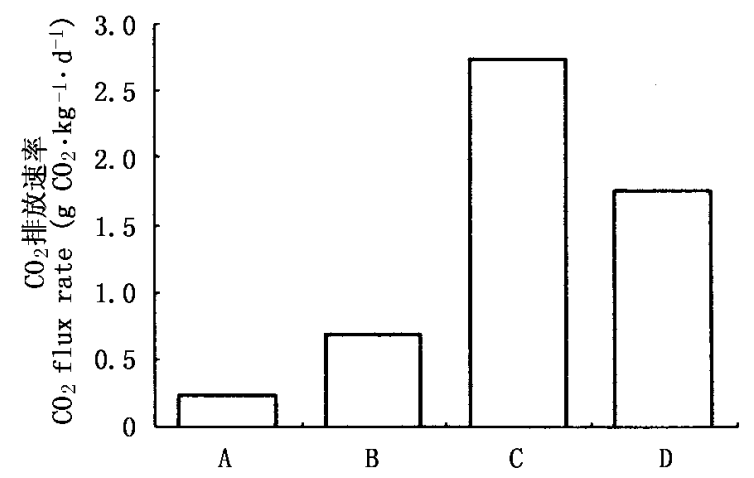

图 4 不同管理措施草地的土壤 $\mathrm{CO}_{2}$ 排放速率

Fig.4 $\mathrm{CO}_{2}$ flux rate of pastures under different managements A, B, C, D: 同图 1 See Fig. 1

表 4 总硝化速率和净硝化速率的比较

Table 4 Comparison of gross nitrification and net nitrification rate of pastures under different managements

\begin{tabular}{lcc}
\hline $\begin{array}{c}\text { 草地类型 } \\
\text { Types of pasture }\end{array}$ & $\begin{array}{c}\text { 总硝化速率 } \\
\text { Gross nitrification rateNet nitrification rate } \\
\left(\mathrm{mg} \mathrm{N} \cdot \mathrm{kg}^{-1} \cdot \mathrm{d}^{-1}\right)\end{array}$ & $\begin{array}{c}\text { 净硝化速率 } \\
\left(\mathrm{mg} \mathrm{N} \cdot \mathrm{kg}^{-1} \cdot \mathrm{d}^{-1}\right)\end{array}$ \\
\hline 天然放牧地 Natural pasture & $6.66 \pm 0.38$ & $0.25 \pm 0.32$ \\
围栏草地 Fenced pasture & $7.40 \pm 1.20$ & $0.08 \pm 0.04$ \\
翻耕草地 Tilled pasture & $33.92 \pm 3.76$ & $0.49 \pm 0.05$ \\
人工草地 Artificial grassland & $9.44 \pm 1.52$ & $0.47 \pm 0.07$ \\
\hline
\end{tabular}


过改变环境因子, 改变了土壤微生物的生物量和活 性以及调落物状况 (Holt, 1997; Smolander et al., 1998), 从而使硝化作用增强。土壤中较高的 $\mathrm{NO}_{3}{ }^{-}$$\mathrm{N}$ 含量, 意味着有更多的潜在含氮气体和淋溶损失 （Vitousek et al.，1979）。同时,大量 $\mathrm{NO}_{3}{ }^{-}-\mathrm{N}$ 的存在 也暗示着 $\mathrm{NO}_{3}{ }^{-}-\mathrm{N}$ 可能也是高寒地区植物和微生物 $\mathrm{N}$ 的重要来源, 正像在北极圈附近寒冷地区得出的 研究结果那样 (Körner, 1999)。

但是人类干扰历史似乎不是影响土壤氮和碳转 化速率的主要因素, 因为围栏草地、翻耕草地和人工 草地 3 种去除原来放牧干扰的草地, 其反硝化、总硝 化、 $\mathrm{CO}_{2}$ 和 $\mathrm{N}_{2} \mathrm{O}$ 排放速率都远远高于天然放牧草地, 而且它们之间的差异也较大。人类的管理措施或利 用方式对土壤氮和碳转化速率的影响可能更为直接 和关键, 它驱动着土壤氮和碳库的变化, 但这种影响 最终反映在有机质和全氮含量变化上会有一定的时 间迟滞。

3.2 不同管理措施对土壤氮、碳库及其转化速率的 影响

围栏草地的有机质、全氮以及反硝化、总硝化和 $\mathrm{CO}_{2}$ 排放速率都明显地高于天然放牧草地, 因此, 放 牧可能主要通过两个方面影响土壤的这些特征: 一 是减少归还于土壤的调落物量, 从而使矿化所需的 底物和微生物的碳源、能源——有机质和全氮含量 降低(只有 69.71 和 $3.74 \mathrm{~g} \cdot \mathrm{kg}^{-1}$, 分别是围栏草地的 $62 \%$ 和 $63 \%$ )。二是长期的牲畜踩踏使得土壤紧 实, 氧气扩散受到限制, 土壤微生物活动力不强, 甚 至数目显著减少 (Holt, 1997; 柳丽萍和廖仰南, 1997）。以上两方面同时也可能是去除放牧干扰后， 围栏草地所测各项指标明显偏高的主要原因。

草地在连续两年春季 (4 月)翻耕后, 夏季 ( 7 月 和 8 月) 的有机质和全氮含量都下降了, 硝化以及 $\mathrm{N}_{2} \mathrm{O}$ 和 $\mathrm{CO}_{2}$ 排放速率却大幅度增加, 分别是翻耕前 的 4.6.1.8 和 3.7 倍。这与 Estavillo 等(2002) 的研 究结论相似,他们的研究也表明翻耕会在短时间内 提高 $\mathrm{N}_{2} \mathrm{O}$ 和 $\mathrm{CO}_{2}$ 排放量; Hadi 等(2000) 的研究也发 现 $\mathrm{N}_{2} \mathrm{O}$ 的排放速率在泥碳土翻耕后的半年时间内 大大增加。出现这种现象, 是因为翻耕后增加了土 壤孔隙度和通透性, 使土壤有机质和微生物细胞组 织暴露于空气当中, 从而增加了与空气中氧的接触 面积 (Dao, 1998), 从而在微生物碳源、能源充足和土 壤含水量较高 $\left(0.37 \mathrm{~kg} \cdot \mathrm{kg}^{-1}\right)$ 的情况下, 加快了植物 残体的分解以及氮的矿化和固定。但是, 这种矿化 作用的增强会导致有机质的丧失 (Gupta \& Germida,
1988) 和温室气体排放的增加 (Estavillo et al., 2002)。所以虽然春季翻耕常被作为人工草场建设 中提高作物产量的重要管理措施之一, 但它同时也 承担着巨大的环境风险一大大增加了 $\mathrm{N}_{2} \mathrm{O} 、 \mathrm{CO}_{2}$ 的排放和 $\mathrm{NO}_{3}{ }^{-}-\mathrm{N}$ 的淋溶, 减少了土壤中碳的吸存 量。尤其是翻耕草地对升温的敏感 (Sun et al., 2005), 更使得春季翻耕在环境温度升高的背景下承 受着更多的风险。因此, 从增加温室气体排放和 $\mathrm{NO}_{3}{ }^{-}$的淋溶以及减少土壤碳吸存的角度, 建议在青 藏高原东部高寒牧区的人工草地建设中慎重选择翻 耕措施。加之高寒草地固有的生草层在翻耕后往往 很难得到恢复, 而生草层下的沙质基底又成为草地 沙化的主要物质来源 (特别是在若尔盖地区), 所以, 不一定所有旨在恢复退化草地的良好愿望就不会带 来新的退化或负面的环境影响。

人工草地中氮肥的施用直接导致了土壤有效氮 特别是 $\mathrm{NO}_{3}{ }^{-}-\mathrm{N}$ 含量的升高, 而且土壤有机质和全 氮含量大大提高, 分别是围栏草地的 1.3 和 1.9 倍, 是天然放牧草地的 2.1 和 3.1 倍。另一方面, 人工 草地的总硝化、反硝化、 $\mathrm{N}_{2} \mathrm{O}$ 和 $\mathrm{CO}_{2}$ 排放速率要高于 围栏草地, 更远远高于天然放牧草地。Ruser 等 (1998) 的研究也表明, 长期大量施用氮肥 (30g N • $\left.\mathrm{m}^{-2} \cdot \mathrm{a}^{-1}\right)$ 可使沙质土草地的 $\mathrm{N}_{2} \mathrm{O}$ 排放量增加约 $60 \%$, 使粘质土草地的排放量增加约 $30 \%$; 少量施 用氮肥 $\left(0.5 \sim 2.0 \mathrm{~g} \mathrm{~N} \cdot \mathrm{m}^{-2} \cdot \mathrm{a}^{-1}\right)$ 不会立即增加沙 质土草地 $\mathrm{N}_{2} \mathrm{O}$ 的排放量, 但是却能显著增加粘质土 草地 $\mathrm{N}_{2} \mathrm{O}$ 的排放量。

与管理措施对氮、碳库及其转化速率的效应相 对应, 从表 3 可以发现, 不同管理措施条件下,草地 土壤 $\mathrm{N}_{2} \mathrm{O}$ 排放速率差异不显著 (除了翻耕草地远高 于其它类型土壤), 而有机质、全氮以及总硝化、反硝 化和 $\mathrm{CO}_{2}$ 排放速率的差异非常明显。也就是说, 不 同的指标对管理措施变化的敏感程度是不同的,有 机质、全氮以及总硝化、反硝化和 $\mathrm{CO}_{2}$ 排放速率在反 映施肥、围栏和翻耕等管理措施差异时更为敏感。

3.3 总硝化速率和净硝化速率在反映川西北草地 土壤硝化状况上的比较

净硝化速率是一段时间始末 $\mathrm{NO}_{3}{ }^{-}-\mathrm{N}$ 含量的差 值, 而 $\mathrm{NO}_{3}{ }^{-}-\mathrm{N}$ 含量是包括硝化作用以及植物吸收、 微生物固定、反硝化作用、淋溶作用和其它化学反应 等多个过程的动态平衡结果。总硝化速率反映一段 时间内到底有多少 $\mathrm{NH}_{4}{ }^{+}-\mathrm{N}$ 转化成了 $\mathrm{NO}_{3}{ }^{-}-\mathrm{N}$ 。在 以前的研究中, 虽然总硝化速率是人们需要的数据, 但是为了避免应用 ${ }^{15} \mathrm{~N}$ 稀释技术, 常用净硝化速率代 
替总硝化速率来反映土壤的硝化状况。现在, BaPS 提供了一种可靠、简便、廉价的方法。

研究结果显示, 研究区域土壤净硝化速率与总 硝化速率相差很大, 后者是前者的 20 93 倍。而 且, 总硝化速率和反硝化速率在各种管理措施条件 下草地土壤中的相关性较好 ( $R^{2}$ 为 $0.503 \sim 0.861$ )。 原因显而易见, 总硝化的产物正是反硝化的底物。 所以作者认为, 测定的净硝化速率值不能真实反映 土壤硝化和 $\mathrm{NO}_{3}{ }^{-}-\mathrm{N}$ 的周转情况, 总硝化速率才是 反映土壤硝化状况的恰当指标。这与 Davidson 等 (1992)及 Stark 和 Hart (1997) 的论断一致。

\section{4 结 论}

通过以上的分析和讨论, 可以得出以下主要结 论: 草地经营管理措施对土壤氮、碳库及其转化速率 有显著影响。围栏草地和人工草地比天然放牧草地 土壤的有机质和全氮含量高得多, 相应的土壤氮和 碳的转化速率也加快。春季翻耕虽然常被用来作为 一种提高作物产量 (如牧草) 的管理措施, 但它同时 也承担着巨大的环境风险, 即大大增加了 $\mathrm{CO}_{2}$ 和 $\mathrm{N}_{2} \mathrm{O}$ 排放和 $\mathrm{NO}_{3}{ }^{-}$淋溶的可能性。由于总硝化速率 是净硝化速率的 20 93 倍, 测定的净硝化速率值不 能真实反映土壤硝化和 $\mathrm{NO}_{3}{ }^{-}-\mathrm{N}$ 的周转情况, 总硝 化速率才是反映高寒地区土壤硝化状况的恰当指 标。

\section{参 考 文 献}

Hadi A, Inubushi K, Purnomo E, Razie F, Yamakawa K, Tsuruta H (2000) . Effect of land-use changes on nitrous oxide emission from tropical peatlands. Chemosphere-Global Change Science, 2, 347 358 .

Chen WN (陈文年), Wu N (吴宁), Luo P(罗鹏) (2002). Grassland resources and mountain pastoralism development on the upper reaches of Minjiang River. Sichuan Grassland (四川草 原) , 9, 1-5. (in Chinese with English abstract)

Dao TH(1998). Tillage and crop residue effects on carbon dioxide evolution and carbon storage in a Paleustoll. Soil Science Society of America Journal, 62,250 - 256.

Davidson EA, Hart SC, Firestone MK(1992) . Internal cycling of nitrate in soils of mature coniferous forest. Ecology, 73, 1148 1156.

Estavillo JM, Merino P, Pinto M, Yamulki S, Gebauer G, Sapek A, Corré W(2002) . Short term effect of ploughing a permanent pasture on $\mathrm{N}_{2} \mathrm{O}$ production from nitrification and denitrification. Plant Soils , 239, $253-265$.

Francis GS, Haynes RJ, Williams PH(1995) . Effects of the timing of ploughing in temporary leguminous pastures and two winter cover crops on nitrogen mineralization, nitrate leaching and spring wheat growth. Journal of Agricutural Science, 124,1 - 9 .

Franzluebbers AJ(1999). Potential C and N mineralization and microbial biomass from intact and increasingly disturbed soils of varying texture. Soil Biology and Biochemistry, 31,1083 - 1090.

Gupta VVSR, Germida JJ (1988) . Distribution of microbial biomass and its activity in different soil aggregate size classes as affected by cultivation. Soil Biology and Biochemistry, 20,777 - 786 .

Hachl E, Zechmeister-Boltenstern S, Kandeler E (2000). Nitrogen dynamics in different types of pasture in the Austrian Alps. Biology and Fertility of Soils, 32,321 - 327 .

Holt JA (1997) . Grazing pressure and soil carbon, microbial biomass and enzyme activities in semiarid Northeastern Australia. Applied Soil Ecology, 5, 143 - 149.

Ingwersen J, Butterbach-Bahl K, Gasche R, Richter O, Papen H (1999) . Barometric pressure seperation: new method for quantifying nitrification, denitrification, and nitrous oxide sources in soils. Soil Science Society of American Journal, 63, 117 - 128.

Knoepp JD, Swank WT (1995) . Comparison of available soil nitrogen assays in control and burned forested sites. Soil Science Society of America Journal, 59, 1751 - 1754.

Körner C(1999). Alpine Plant Life-Functional Plant Ecology of High Mountain Ecosystems 1st edn. Spinger-Verlag, Heidelberg, 149 -152 .

Liu LP(柳丽萍), Liao YN(廖仰南) (1997). Biological characteristics and biodiversity of the soil microorganisms in Leymus chinensis and Stipa grandis steppe under different grazing intensities. Research on Grassland Ecosystem (草原生态系统研究), 5, 70 - 79. (in Chinese)

Liu SQ(刘世全) (1996). Regional Soil Geography (区域土壤地 理) 1st edn. Sichuan University Press, Chengdu, 210 - 251. (in Chinese)

Lu RK (鲁如昆) (2000). Analytic Handbook of Soil Agriculture Chemistry (土壤农业化学分析手册) 1st edn. Chinese Agricultural Science and Technology Press, Beijing, 146 - 165. (in Chinese)

Pang XY(庞学勇), Hu H(胡泓), Qiao YK(乔永康), Pan KW (潘开文), Liu SQ(刘世全), Chen QH(陈庆恒), Liu Q(刘 庆) (2002). Nutrient distribution and cycling of artificial and natural subalpine spruce forests in western Sichuan. Chinese Journal of Applied and Environmental Biology (应用与环境生物 学报), 8, 1-7. (in Chinese with English abstract)

Ruser R, Flessa H, Schilling R, Steindl H, Beese F (1998). Soil compaction and fertilization effects on nitrous oxide and methane fluxes in potato fields. Soil Science Society of America Journal, $62,1587-1595$.

Smolander A, Priha O, Paavolainen L, Steer J, Mälkönen E(1998) . Nitrogen and carbon transformations before and after clear-cutting in repeatedly N-fertilized and limed forest soil. Soil Biology and Biochemistry, 30, 477 - 490 .

Stark JM, Hart SC (1997). High rates of nitrification and nitrate turnover in undisturbed coniferous forests. Nature , 385, 61 - 64 .

Sun G, Wu N, Luo P (2005). Soil N pools and transformation rates under different land uses in a subalpine forest-grassland ecotone. Pedosphere, 15(1), $52-58$.

Vitousek PM, Gosz JR, Grier CC, Melillo JM, Reiners WA, Todd RL (1979). Nitrate losses from disturbed ecosystems. Science, 204,469-474.

Wu N(吴宁), Liu ZG (刘照光) (1998). Probing into the causes of geographical pattern of subalpine vegetation on the eastern Qinghai-Tibetan Plateau. Chinese Jouranl of Applied and Environmental Biology (应用与环境生物学报), 4, 290 - 297. (in Chinese with English abstract) 